\title{
BMJ The process and costs of publishing Open medical journals in Sri Lanka: an economic evaluation
}

\author{
P Ranasinghe, ${ }^{1}$ Y S Perera, ${ }^{2}$ A M Abeygunasekara ${ }^{1}$
}

To cite: Ranasinghe $P$, Perera YS, Abeygunasekara AM. The process and costs of publishing medical journals in Sri Lanka: an economic evaluation. BMJ Open 2011:1:e000057. doi:10.1136/bmjopen-2011000057

- Prepublication history for this paper is available online. To view these files please visit the journal online (http://bmjopen.bmj.com)

Received 8 January 2011 Accepted 20 May 2011

This final article is available for use under the terms of the Creative Commons Attribution Non-Commercial 2.0 Licence; see http://bmjopen.bmj.com

${ }^{1}$ Colombo South Teaching Hospital, Kalubowila, Sri Lanka

${ }^{2}$ The National Hospital of Sri Lanka, Colombo, Sri Lanka

Correspondence to Dr Priyanga Ranasinghe; rana90210@yahoo.com

\begin{abstract}
Objectives: Medical journals have contributed to the advancement of medicine by helping to disseminate scientific knowledge and providing a forum for medical communities to debate issues in depth. To the authors' knowledge, there are no studies examining the process of medical journal publication in developing Asian countries. The authors analysed the process and costs of publishing medical journals in Sri Lanka,

a developing country in South Asia.
\end{abstract}

Methods: Data were collected by interviewing the editors and perusing the records at the editorial offices of the respective medical journals. Articles published in 2009 (or 2008 for journals not published in 2009) were analysed by perusing the respective journals.

Results: A total of 44 medical journals were published in Sri Lanka's history, of which only 28 journals remained in publication after 2007. A majority (54\%) of the journals published after 2007 were published once per year. Seventeen journals in publication after 2007 were published in paper version only, and 11 journals were also available online. The mean cost of printing one issue was Sri Lankan Rupees (LKR) 97720 (US\$888) (range LKR $28000-270000$ ). The cost of distribution ranged from LKR 2000 to 140000 (US\$18-1273). The mean cost of publishing one article was LKR 6646 (US\$60). A total of 456 articles were published in 2009 (/2008). The total number of pages published was 1723 .

Conclusion: The infrastructure for medical journal publishing in Sri Lanka has many good qualities such as free access, minimum charges for authors and potential for online availability. The journals are solely academic (non-profit), but the costs remain high.

\section{INTRODUCTION}

Scientific journals began in the 17th century with the French Journal des Savants and the British Philosophical Transactions of the Royal Society. ${ }^{1}$ General medical journals began at the end of the 18th century and specialist medical journals at the beginning of the 20th century. Medical publications in Sri Lanka began in the late 19th century; the Journal of the Ceylon Branch of the British Medical Association (forerunner to The Ceylon Medical Journal)

\section{ARTICLE SUMMARY}

Article focus

- To analyse the process and costs of publishing medical journals in a developing country.

- To identify a list of medical journals published in the country.

- To analyse the number and types of articles published in recent Sri Lankan medical journals.

Key messages

- Sri Lankan medical journals are freely accessible with minimum charges for authors.

- Sri Lankan medical journals are solely academic (non-commercial) and non-profit in nature.

- The publication costs remain high.

Strengths and limitations of this study

- There is a lack of a comprehensive list of medical journals in the country.

- The limited number of publications from the fields of allied health sciences (nursing, pharmacy and physiotherapy) were not included.

was among the first medical journals published in the country. Medical journals have contributed immensely to the advancement of medicine by helping to disseminate scientific knowledge and providing a forum for medical communities to debate issues in depth. In addition, medical journals have helped medical practitioners to stay up to date on current practices related to their profession.

The cost of producing the first copy for a good- to high-quality journal in the UK has been estimated to be approximately $\$ 2000$. $^{2}$ Prices for US science journals rose $11 \%$ from 1960 to 1995 in constant dollars. ${ }^{3}{ }^{4}$ Van Orsdel and Born reported that US journals prices rose $8.8 \%$ from 1995 to $1996 .^{5}$ US journal prices increased $9.6 \%$ from 2003 to 2007, and non-US journals prices increased $9.2 \%$ during the same time in constant dollars. ${ }^{6}$ Reasons given for such prices increases are an increase in the size of the journals (including non-article content), the falling number of subscriptions, 
resource-cost inflation and the move away from authorside charges in the $1980 \mathrm{~s} .{ }^{7}$ The increased costs have resulted in significant journal price increases, hampering the ability of libraries, institutes and investigators from acquiring publications necessary for research and education. ${ }^{8} 9$

The situation in relation to the publication of medical journals in developing countries such as Sri Lanka is different, as most medical journals published locally are underfunded, lack high-quality articles and are invisible to the rest of the world. ${ }^{10}$ To our knowledge, no studies have examined the process of publishing medical journals in developing countries in Asia. The primary objective of the present study was to analyse the process and costs of publishing medical journals in Sri Lanka, a developing country in South Asia. Secondary objectives included identifying a list of medical journals published in the country and analysing the number and different types of articles published recently in medical journals in Sri Lanka.

\section{METHODS}

\section{Journal identification}

In the absence of any established method for obtaining an exhaustive list of all medical journals in Sri Lanka, the list of medical journals published in Sri Lanka was compiled using: (1) The Union list of periodical holdings of Health Science libraries in Sri Lanka 2001, published by Health Literature, Library and Information Services (HELLIS) Network Sri Lanka; ${ }^{11}$ and (2) medical periodicals catalogues available at the following libraries: Faculty of Medicine, Colombo; Postgraduate Institute of Medicine, Colombo; and Sri Lanka Medical Library. Journals published in either year 2008 or 2009 were considered for the cost analysis, and journals that were not published after 2007 were excluded, as the cost of publication may have changed significantly in recent years. In addition, journals from the allied health sciences were also excluded.

\section{Cost analysis}

The costs for printed journals were analysed under two basic categories, 'direct costs' and 'indirect costs. ${ }^{12}$ Direct costs were (1) editorial costs (for the selection and review of articles, the manuscript management system and copy-editing); (2) cost of printing; (3) distribution costs (including postage, packing and shipping costs); and (4) overhead costs (maintenance of an office and staff). The indirect costs were costs involved in administration, marketing and financing. For electronically published journals, there was no cost of printing or distribution. The editorial costs, overhead costs and indirect costs were minimal in the Sri Lankan context.

Costs were also be divided as fixed costs and variable costs. Fixed costs were those involved in manuscript processing such as editing, preparing special graphics and proofreading (ie, costs remain fixed for a journal, regardless of the number of subscribers). The variable costs were those involved in printing and distribution of the journal (ie, costs vary by the number of subscribers). In the Sri Lankan context, the fixed costs were minimal, as editorial services were provided free of charge; hence the total variable costs were the sum of the cost of printing and distribution.

\section{Data collection and analysis}

The study was conducted between June and July 2010 . Data were collected by an interviewer-administered questionnaire. A member of the study team interviewed editors of the respective journals, and exact figures for monetary data were obtained by perusing records at the respective journal offices. Data on the number of issues per year, copies printed per issues, costs of printing a single issue, other costs and avenues of income were collected, while the types and numbers of articles published in 2009 (or 2008 for journals not printed in 2009) were analysed by perusing the respective journals. The consent for publication of data was obtained from the editors of the respective journals. Data were analysed using SPSS V 14.

\section{RESULTS}

A total of 44 medical journals were identified as being ever published in Sri Lanka by the above-mentioned journal identification method, and all journals were published in English. A list of journals identified as being ever published in Sri Lanka is given in box 1 . Twenty-eight journals were being published after 2007, on which the following analysis is based. Fifteen (54\%) journals were published once per year (annually). Seventeen journals $(61 \%)$ were published in paper version only, while nine journals were published online in addition to paper publication. Two journals (7\%) were published exclusively in the electronic format. All 11 electronically published journals allowed free online access to their articles. The number of copies printed per issue ranged from 100 to 8000 (mean 636). Only two journals published more than 1000 copies per issue (The Sri Lanka Prescriber and The Ceylon Medical Journal).

The mean cost of printing one issue was Sri Lankan Rupees (LKR) 97720 (US\$888). The cost range was LKR 28000-270000 (US\$254-2454). Most of the journals were distributed free of charge, while seven journals carried a selling price which ranged from LKR 20 to 400 (US $\$ 0.2-4)$. The main forms of distribution were collection by subscribers from the respective journal office $(67.9 \%)$, postage $(46.4 \%)$ and courier $(14.3 \%)$ respectively. The cost of distribution ranged from LKR 2000 to 140000 (US\$18-1273). Thirteen (52\%) journals did not use any paid modes of distribution. There were no editorial costs involved for all the journals, as editorial services and peer review were provided free of charge. Only one journal was hosted in a dedicated office space (The Ceylon Medical Journal), while all other journals were hosted at the premises of the respective college or association. Thus, the total cost of journal publication was a sum of the cost of printing and cost of distribution. Table 1 provides a breakdown of each journal's costs. 


\section{Box 1 Medical journals ever published in Sri Lanka}

1. Anuradhapura Medical Journa/

2. Batticaloa Medical Journal

3. Bulletin of the Medical Research Institute of Sri Lanka*

4. Bulletin of Ceylon academy of Postgraduate Medicine ${ }^{\star}$

5. Ceylon Journal of Medical Sciences*

6. Ceylon Medical Journal

7. Galle Medical Journal

8. Government Medical Officers Association Medical Journal"

9. Jaffna Medical Journal${ }^{\star}$

10. Journal of the Lady Ridgeway Hospital for Children*

11. Journal of Diagnostic Pathology*

12. Journal of Ruhunu Clinical Society

13. Journal of the Ceylon College of Physicians

14. Journal of the Ceylon Public Health Association*

15. Journal of the Clinical Society, General Hospital, Colombo*

16. Journal of the College of Ophthalmologist of Sri Lanka

17. Journal of the Colombo General Hospita/ ${ }^{*}$

18. Journal of the Medical Research Institute of Sri Lanka*

19. Kurunegala Medical Journal

20. Medical Topics*

21. Medical Research Institute Sri Lanka-Research Publications ${ }^{\star}$

22. Respire

23. Sri Lankan Family Physicians

24. Sri Lanka Journal of Anaesthesiology

25. Sri Lanka Journal of Bio-Medical Informatics

26. Sri Lanka Journal of Child Health

27. Sri Lanka Journal of Community Physicians

28. Sri Lanka Journal of Critical Care

29. Sri Lanka Journal of Haematology

30. Sri Lanka Journal of Medicine

31. Sri Lanka Journal of Orthopaedics

32. Sri Lanka Journal of Psychiatry

33. Sri Lanka Journal of Surgery

34. Sri Lanka Journal of Urology

35. Sri Lanka Practitioner*

36. Student Medical Journal

37. The Bulletin of the Sri Lanka College of Microbiologists

38. The Sri Lanka Journal of Dermatology

39. The Sri Lanka Journal of Medical Administration

40. The Sri Lanka Journal of Obstetrics and Gynaecology

41. The Sri Lanka Journal of Venereology

42. The Sri Lanka Prescriber

43. Transactions of the Society of Medical Officer of Health, Ceylon*

44. Uva Medical Journal

*Journals not published after 2007.

The total annual cost of publishing medical journals in Sri Lanka was LKR 5522100 (US\$50 201). The mean cost of printing one copy per journal per issue was LKR 308 (US\$3). The mean cost of publishing one article per issue per journal was LKR 6646 (US\$60). The average cost of printing one page per issue per journal was LKR 1848 (US\$17). The main sources of income were advertisements/donations only $(35.7 \%)$ and funds from the college/association only $(39.3 \%)$ or both $(25.0 \%)$.
The total number of articles (number of pages) published for year 2009 (or 2008 for journals not published in 2009) for the 28 medical journals were as follows: editorial (30 (51)), leading/review articles (49 (260)), research papers $(120(577))$, brief reports (23 (44)), case reports $(88(190))$ and other articles (146 (600)). A journal on average had 16 articles (range $5-55$ ) and carried 61 (range 26-238) pages. A total of 456 articles were published by the respective journals per year (considering year 2009 or 2008 for journals not published in 2009). The total number of pages published was 1723 . Twenty-three articles $(5.0 \%)$ were contributions from foreign countries (India 9, Australia 6, UK 5, Pakistan 1, Iran 1 and Philippines 1).

\section{DISCUSSION}

The current global market of scientific publication is a complex one that has evolved over hundreds of years. Searches of UlrichsWeb in 2008 show a total of 219774 active journals, of which 64620 are active and academic/ scholarly (Boolean search) and 24059 active and reference journals. ${ }^{4}$ Working from Ulrich's and the Thompson (SIS) citation index, it is estimated that 23750 journals published in 2006 yielded a total of 1350000 peerreviewed journals. ${ }^{13}$ Once published, these journals are searched, read and referenced by readers and researchers worldwide. These scientific journals for analytical purposes can be divided into two broad categories commercial publications and non-commercial publications. The commercial publishers seek to maximise profit through publishing, while non-commercial/academic publishers (universities and academic societies) as in the Sri Lankan context are mainly non-profit institutions whose objectives are usually linked to furthering the interests of their research or professional development. For Sri Lankan journals, the main sources of funding are advertisers, donors and societies/institutions. Their involvement can be susceptible to influence by external factors such as the state of the local or global economy. This therefore could place limits on the ability of Sri Lankan medical journals to maintain their operations.

There were 28 medical journals in Sri Lanka which published issues in 2008/2009. In 2005, the whole of Africa had only 59 medical journals published in 33 countries. ${ }^{10}$ The average cost of publishing one article in Sri Lanka was LKR 6646 (US\$60), while the cost of printing one page was LKR 1848 (US\$17). In contrast the estimated cost of scientific publications in the $\mathrm{UK}^{2}$ and $\mathrm{USA}^{14}$ is US\$2000 (LKR 220000) and US\$3000 (LKR $330000)$ respectively per article. The comparatively low cost for Sri Lankan journals can be attributed to the lack of expenses related to copy-editing, peer-review and dedicated staff, and office maintenance. However, the savings from these may compromise the quality of peer review, copy-editing and punctuality of publications. Though these are relatively lower than the figures from the developed world, publishing an article in a Sri Lankan medical journal incurs a significant cost to the publisher. 
Table 1 Publication costs for individual journals

\begin{tabular}{|c|c|c|c|c|}
\hline \multirow[b]{2}{*}{ Name of journal (issues per year) } & \multirow{2}{*}{$\begin{array}{l}\text { Copies per } \\
\text { issue }\end{array}$} & \multirow[b]{2}{*}{ Mode of publication } & \multicolumn{2}{|c|}{$\begin{array}{l}\text { Total costs } \\
\text { (Sri Lankan Rupees) }\end{array}$} \\
\hline & & & Per issue & Annual \\
\hline Batticaloa Medical Journal (1) & 500 & Printed & 94000 & 94000 \\
\hline Ceylon Medical Journal (4) & 2000 & Printed and online & 205000 & 820000 \\
\hline Galle Medical Journal (1) & 225 & Printed and online & 140000 & 140000 \\
\hline Journal of the Ceylon College of Physicians (1) & 600 & Printed & 340000 & 340000 \\
\hline Journal of the College of Ophthalmologist of Sri Lanka (2) & 250 & Printed & 120000 & 240000 \\
\hline Journal of the Ruhunu Clinical Society (1) & 200 & Printed & 62000 & 62000 \\
\hline Kurunegala Medical Journal (1) & 200 & Printed & 55000 & 55000 \\
\hline Respire (2) & 350 & Printed & 170000 & 340000 \\
\hline Sri Lanka Journal of Anaesthesiology (2) & 250 & Printed and online & 72500 & 145000 \\
\hline Sri Lanka Journal of Child Health (4) & 250 & Printed and online & 100000 & 400000 \\
\hline Sri Lanka Journal of Community Physicians (2) & 350 & Printed & 69000 & 138000 \\
\hline Sri Lanka Journal of Haematology (1) & 200 & Printed & 100000 & 100000 \\
\hline The Sri Lanka Journal of Orthopaedic Surgery (1) & 100 & Printed & 30000 & 30000 \\
\hline Sri Lanka Journal of Psychiatry (2) & 200 & Printed & 28000 & 56000 \\
\hline Sri Lanka Journal of Surgery (2) & 450 & Printed and online & 108000 & 216000 \\
\hline Sri Lanka Journal of Urology (1) & 200 & Printed and online & 50000 & 50000 \\
\hline Sri Lanka Journal of Medicine (2) & 300 & Printed and online & 105000 & 210000 \\
\hline Sri Lankan Family Physician (1) & 400 & Printed & 100000 & 100000 \\
\hline Student Medical Journal (1) & 100 & Printed & 40100 & 40100 \\
\hline The Bulletin of the Sri Lanka College of Microbiology (1) & 175 & Printed & 94000 & 94000 \\
\hline The Sri Lanka Journal of Medical Administration (1) & 300 & Printed & 75000 & 75000 \\
\hline The Sri Lanka Journal of Obstetrics and Gynaecology (4) & 300 & Printed and online & 120000 & 480000 \\
\hline The Sri Lanka Journal of Venereology (1) & 250 & Printed & 50000 & 50000 \\
\hline The Sri Lanka Prescriber (4) & 8000 & Printed and online & 270000 & 1080000 \\
\hline The Sri Lankan Journal of Dermatology (1) & 150 & Printed & 137000 & 137000 \\
\hline Uva Medical Journal (1) & 250 & Printed & 60000 & 60000 \\
\hline Total & & & 2764600 & 5552100 \\
\hline
\end{tabular}

In addition, in a developing country such as Sri Lanka, where the per capita monthly income is LKR 9100 (US $\$ 83)^{15}$ and where a majority of the research work is selffunded, the cost of publication per article of LKR 6646 (US\$60) is substantially high. Authors, researchers, academic and funding organisations, and the government of Sri Lanka should be aware of this. Despite the availability of international journals, local journals still have a vital role to play in disseminating local knowledge, translating it into policy and practice, and contributing to national development. ${ }^{16}$ Therefore, all stake holders, especially the government and funding organisations, should recognise the importance of medical journals' potential as a tool for reduction in health inequity and poverty. Publication of medical journals should be supported financially by the state institutes, too, to improve their quality and sustainability. This would help the journals to be published more frequently and punctually, which in turn would foster local research and increase the publishing capacity of Sri Lanka.

In the Sri Lankan model of journal publication, the total fixed costs of publication are minimal, as editorial services, peer review and proofing services are volunteered. Hence, the costs of publishing are mainly dependent on variable costs. This cost distinction is important in comparing publishing practices. Fixed costs of both print and electronic journals are recovered in three main ways: through subscriptions, author-side payments or contributions of time by editors and others, as in the Sri Lankan setting. Journal printing costs elsewhere tend to be in the $\$ 30-50$ per subscription range, and distribution costs in the \$10-20 range. The variable cost per article in a subscription is about $\$ 0.40$, and the per-article page in a subscription is under $\$ 0.04$. The variable costs of print journals are recovered as part of subscription prices, or, for society journals, personal subscriptions are recovered through member fees. The high price of some journals is due to a very large fixed cost (when there are many articles) that is recovered by a small number of subscribers.

The Sri Lankan medical journals averaged 16 articles (range 5-55) and 61 pages (range 26-238) per journal or about 3.8 pages per article, which is relatively small in comparison with international life science journals including medicine. In addition, only $5.0 \%$ of the contributions were from foreign countries, of which $39 \%$ were from neighbouring India. Out of the 28 journals studied in this analysis, only one of the journals (Ceylon Medical Journal) was indexed in PubMed and carried an impact factor. Thus, although the Sri Lankan model may 
foster research publications and local dissemination of knowledge, international contributions and accessibility to the international audiences remain low. Making journals accessible online is one probable solution this issue. Online publication would also help to reduce the printing and distribution costs. ${ }^{12}$ In addition, the availability of appropriate software makes it possible to make the submission of articles, peer review process and copyediting to be done online conveniently for both authors and reviewers. Online publication on a live website would increase the visibility of the journal and its contents. This may help to alleviate the disadvantages of not being included in the indexing systems run by the developed world. The International Network for the Availability of Scientific Publications, a non-profit-making organisation based in the UK, maintains a website for Sri Lankan scientific journals (Sri Lanka Journals Online). At present, there is no extra cost for the journals to be included in this website. Eleven of the Sri Lankan medical journals are available online through this website. The journal website has gained increasing popularity at both national and international levels. Google Analytics shows that from 23 September to 31 December 2008, there were 1364 visits from 82 different countries. In contrast, from 1 January to 30 June 2010, there were 55756 visits from 186 different countries: the top four sources for visitors were: Sri Lanka (13843 from seven cities), India (7740 from 130 cities), USA (6424 from 2264 cities) and UK (3796 from 368 cities). The United Nations' repeated calls to provide universal access to the scientific and medical literature have not been heeded by most journals in the world. ${ }^{16}$ However, all Sri Lankan medical journals which are available online allowed free access to all their articles. Although this may not be a genuine form of openaccess publication, this is a healthy trend which should be continued and fostered for wider dissemination of knowledge. The editors and publishers of other medical journals in Sri Lanka, too, should work towards making their journals available online using the Sri Lanka Journals Online website. With online publication, it may be possible to reduce the number of copies printed and thereby to reduce the escalating printing expenses. One drawback of the online publishing system would be the reluctance of the traditional researchers and reviewers to accept the computer-based system.

Our study has several limitations. The lack of a comprehensive list of medical journals in the country resulted in authors having to limit their journal search to the aforementioned sources. Thus, there is a possibility of inadvertently non-identifying certain medical journals in print and previously printed. In addition, the limited number of publications from the fields of allied health science (nursing, physiotherapy and pharmacy) were not included in the study.

\section{CONCLUSION}

The Sri Lankan model of publishing medical journals has several good qualities such as free access, minimum charges for authors and potential for online availability.
A majority of Sri Lankan medical journals are solely academic and non-profit in nature. However, the cost of publication remains substantially high. The good qualities of Sri Lankan medical journals should be appreciated and further strengthened by financial support from government institutes and funding organisations. Sri Lankan medical journals should shift from the traditional publishing model to online publications with a minimum number of printed copies to curtail the everincreasing printing and distribution costs. This would increase their visibility in the international arena, too.

Acknowledgements We wish to acknowledge the contribution by DW King, in the revision of the manuscript, and also wish to thank the editors of the respective journals for their support during data collection.

Funding This research received no specific grant from any funding agency in the public, commercial or not-for-profit sectors.

Correction notice This article has been corrected since it was published Online First. The received date has been amended.

Competing interests None.

Contributors All authors were involved in study design, data collection and analysis. PR drafted the initial manuscript. The manuscript was critically reviewed by YSP and AMA. All authors read and approved the final manuscript.

Provenance and peer review Not commissioned; externally peer reviewed.

Data sharing statement No additional data available.

\section{REFERENCES}

1. Smith R. The trouble with medical journals. J Roy Soc Med 2006;99:115-19.

2. Houghton JW, Rasmussen B, Sheehan PJ, et al. Economic implications of alternative scholarly publishing models? Exploring the costs and benefits. Report to the Joint Information Systems Committee. Melbourne, Australia: Victoria University \& Loughborough University, 2009. http://www.jisc.ac.uk/publications/reports/2009/ econmicpublishingmodelsfinalreport.aspx (accessed $1 \mathrm{Feb} 2010$ ).

3. King DW, McDonald DD, Roderer NK. Scientific Journals in the United States: Their Production, Use, and Economics. Stroudsburg, PA: Hutchinson Ross Publishing, 1981.

4. Tenopir C, King DW. Towards Electronic Journals; Realities for Scientists: Librarians, and Publishers. Washington, DC: Special Libraries Association, 2000.

5. Ketcham-Van Orsdel L, Born K. E-Journals come of age: 38th Annual Periodical Price Survey. Library J 1998;123:40-5.

6. Van Orsdel LC, Born K. Serials wars. Library J 2008;132:438.

7. King DW, Alvarado-Albertorio FM. Pricing and other means of charging for scholarly journals: a literature review and commentary. Learned Publishing 2008;21:248-72.

8. Godlee F, Horton R, Smith R. Global information flow. BMJ 2000;321:7767.

9. Barton S. Using clinical evidence. BMJ 2001;322:5034.

10. Siegfried N, Busgeeth K, Certain E. Scope and geographical distribution of African medical journals active in 2005. S Afr Med J 2006;96:533-7.

11. Directory of Health Literature, Library and Information Services (HELLIS) Network Libraries in SRI LANKA. HELLIS Focal Point Library, Faculty of Medicine, University of Colombo, 2006. http:// www.lib.cmb.ac.lk/hellis/hedir.pdf (accessed 10 May 2011).

12. King DW. The cost of journal publishing: a literature review and commentary. Learned Publishing 2007;20:85-106.

13. Bjork BC, Roos A, Lauri M. Global annual volume of peer reviewed scholarly articles and the share available via different open access options. Proceedings of the 12th International Conference on Electronic Publishing. 2008. http://oacs.shh.fi/publications/elpub2008.pdf (accessed 12 Feb 2010).

14. King DW. The Economics of Science Publishing. 30th Annual Annual Forum on Science \& Technology Policy. http://www.aaas.org/spp/rd/ Forum_2005/forum05king.pdf (accessed 12 Feb 2010).

15. Department of Census \& Statistics. Household Income and Expenditure Survey-2009/10 Final Results: 2010. http://www.statistics.gov.lk/ Newsletters/HIES200910FinalBuletin.pdf (accessed 12 Apr 2010).

16. PLoS Medicine editors. How can biomedical journals help to tackle global poverty? PLoS Med 2006;3:e380. 